\title{
Resource Use Efficiency of Cashewnut in West Garo Hills of Meghalaya, India
}

\author{
Lakshmi Dhar Hatai* \\ Department of Basic Science and Humanities, College of Community Science, Central \\ Agricultural University (Imphal), Tura, Meghalaya, India \\ *Corresponding author
}

Keywords

Resource Use

Efficiency,

Cashewnut, Return

to Scale, Meghalaya

Article Info

Accepted:

15 June 2019

Available Online:

10 July 2019

\section{A B S T R A C T}

An attempt has been made to examine the resource use efficiency, marginal value productivity of resources and return to scale of Cashewnut grown by different categories of farmers. Selsella block of West Garo Hills district in Meghalaya was selected purposively and two stage stratified random sampling method was adopted for selection of sample villages and respondents. It was seen that small farms, manures and fertilizers was highly significant at one per cent level of probability and the inputs like raw seed nut, labour, insecticides \& pesticides and irrigation were significant at five per cent level of probability. But in case of miscellaneous expenditures it was not significant. It showed that raw nut, labour, manures and fertilizers and insecticides and pesticides, irrigation have a positive impact towards the income from cashewnut. The ratio MVP and MFC ratio was positive and greater than one. The greater than unit and it is significant in case of inputs like nut, labour, manures and fertilizers, insecticides and pesticides etc. Its significance indicated the possibility of additional use of these inputs to achieve the optimum level.

\section{Introduction}

Cashewnut (Anacardium occidentale L.) is grown mostly around Asia, Africa and Latin America. The average global productivity of cashewnut is about $500 \mathrm{~kg}$ ha-1 while in India it is about $650 \mathrm{~kg} \mathrm{ha}^{-1}$. Cultivated largely as a neglected crop, it ends up as a favourite snack food all over the world. Advancements in propagation, production, management and mechanized processing gained cashew the status of a commercial crop. Ever increasing demand for raw cashew nuts and enhanced interest for commercialization have made this change possible in cashew sector (Venkattakumar, 2009). In India, cashewnut cultivation was mainly confined to Kerala, Karnataka, Maharashtra and Goa along the West Coast, and Tamil Nadu, Andhra Pradesh, Orissa and West Bengal along the East Coast region (DCR, 2011). Meghalaya in the NorthEast region is endowed with diverse agro- 
climatic conditions, rich genetic diversities, vast hydrological resources and pollution free environment that offer a great scope to develop agro-ecosystem a specific technological intervention for diversification of the Agriculture and allied activities viz. horticulture, animal husbandry and fisheries etc. The state displays a distinct ethnic, sociocultural and geographical identity. Cashewnut cultivation is a technically feasible, financially viable and bankable activity in the areas identified suitable for it based on agro-climatic conditions. Cashewnut cultivation is a technically feasible, financially viable and bankable activity in the areas identified suitable for it based on agro-climatic conditions. West Garo Hills District has an area of 4899 ha. Under cashewnut with an estimated annual production of about 12603 Metric tonnes of raw cashew nut (Govt. of Meghalaya, 2012-13). Resource use efficiency in agriculture may be broadly defined to include the concepts of technical efficiency, allocative efficiency and environmental efficiency. An efficient farmer allocates his land, labour, water and other resources in an optimal manner, so as to maximise his income, at least cost, on sustainable basis. However, there are countless studies showing that farmers often use their resources suboptimally. While some farmers may attain maximum physical yield per unit of land at a high cost, some others achieve maximum profit per unit of inputs used (Haque, 2006).

Presently, cashew cultivation in major growing states receives dwindling importance in response to the price fluctuations in arecanut, cocoa, rubber and coconut. Studies covering major cashew growing states have identified the poor adoption of cashewnut production technologies by farmers leading to poor productivity. This drop in productivity coupled with fluctuating prices is forcing cashewnut farmers in the major cashew growing regions to shift to more remunerative cash crops (Ganapathi and Akash, 2013; Sajeev et al., 2014a; Sajeev and Saroj, 2015; Sajeev and Meera Manjusha, 2016; Sajeev and Saroj, 2018; Venkattakumar, 2006; Venkattakumar, 2008). However, Cashewnut cultivation has spread to non-traditional areas like Chhattisgarh, Jharkhand, Gujarat, Bihar and northeast states like Meghalaya, Manipur and Tripura and also to Andaman and Nicobar Islands. India has an area of 1027 thousand ha. under cashew with an estimated annual production of about 725.42 thousand MT of raw cashew nut (2014-15). The objectives of the study were to examine the resource use efficiency, marginal value productivity of resources and return to scale of cashewnut grown by different categories of farmers.

\section{Materials and Methods}

Selsella block of West Garo Hills district was selected purposively due to the concentration of the Cashew growers in this block as compared to other blocks of the district. A two stage stratified random sampling method was adopted for selection of sample villages and respondents. In the first stage a list of villages of the block producing cashewnut was prepared. Out of these villages, four villages namely Dabakgre, Mronggre, Makbilkolgre and Rongramgre were selected at random as primary sample. In the second stage, a completely enumeration of the holdings in each sample villages was made.

The Cashewnut cultivators of these villages were stratified into three size groups (a) Cultivators with 1-2 hectares (Small farmers) (b) 2-4 hectares (Medium farmers) (c) Cultivators having more than 4 hectares (Large farmers). From among the list of the different categories of farm size classes of all the sample villages, 36 small farmers, 30 medium and 24 large farmers were selected at random. Thus in total 90 respondents were selected from the above villages for the study. 


\section{Production Function Analysis}

Production function analysis was used for the estimation of the functional relationship between farm inputs and output. The main objective of the analysis was to find out the efficiency of various factors employed in the production process.

Cobb-Douglas type of production function of the following form was used in the present study.

$\mathrm{Y}=\mathrm{a} \cdot \mathrm{X}_{1}{ }^{\mathrm{b} 1} \cdot \mathrm{X}_{2}{ }^{\mathrm{b} 2} \cdot \mathrm{X}_{3}{ }^{\mathrm{b} 3} \cdot \mathrm{X}_{4}{ }^{\mathrm{b} 4} \cdot \mathrm{X}_{5}^{\mathrm{b} 5} \cdot \mathrm{X}_{6}^{\mathrm{b} 6}$

Where,

$\mathrm{Y}=$ Gross return (in thousand rupees per hectares)

$\mathrm{X}_{1}=$ Cost of raw cashewnut (in thousand rupees per hectares)

$\mathrm{X}_{2}=$ Labour cost (in thousand rupees per hectares)

$\mathrm{X}_{3}=$ Cost of manures and fertilizers (in thousand rupees per hectares)

$\mathrm{X}_{4}=$ Cost of insecticides and pesticides (in thousand rupees per hectares)

$\mathrm{X}_{5}=$ Cost of irrigation (in thousand rupees per hectares)

$\mathrm{X}_{6}=$ Miscellaneous cost which includes cost of, rental value of owned land, interest on working capital, Grading, Packaging and Transportation charges, depreciation etc.(in thousand rupees per hectares)

' $\mathrm{a}$ ' is the intercept term, a constant.

$b_{1}, b_{2}, b_{3}, b_{4}, b_{5}$ and $b_{6}$ are regression coefficients or the production elasticities in this case.

\section{Significance of Regression coefficient}

For testing statistical significance of the regression coefficient or the production elasticities ' $\mathrm{t}$ ' values were calculated by using the formula.

$\mathrm{t}_{\text {cal }}=\frac{\mathrm{b}_{\mathrm{i}}}{\text { S.E. of } \mathrm{b}_{\mathrm{i}}}$

Where,

$b_{i}=$ Regression coefficient of input $x_{i}$

S.E. of $b_{i}=$ Standard error of $b_{i}$

\section{Marginal value products}

A input factor is considered to be used most efficiently if its marginal value product is just sufficient to effect its cost $(\mathrm{MVP}=\mathrm{MFC})$

In Cobb-Douglas production function Marginal value product (MVP) of $X_{i}$ the $i_{\text {th }}$ input is given by formula:

$\overline{\mathrm{M}} \overline{\mathrm{P}}=\mathrm{b}_{\mathrm{i}}\left(\mathrm{Y} / \mathrm{X}_{\mathrm{i}}\right) \mathrm{P}_{\mathrm{y}}$

Where,

$\mathrm{Y}=$ Geometric mean of output $(\mathrm{Y})$

$\mathrm{X}_{\mathrm{i}}=$ Geometric mean of input $\left(\mathrm{X}_{\mathrm{i}}\right)$

$b_{i}=$ Regression coefficient of $\left(X_{i}\right)$

$\mathrm{P}_{\mathrm{y}}=$ Price of the product

\section{Return to scale}

The sum total of production elasticity of all the inputs $\left(\Sigma b_{i}\right)$ indicates returns to scale.

If, $\Sigma b_{i}=1$ : implies operation of constant return to scale

$>1$ : implies operation of increasing return to scale 
$<1$ : implies operation of decreasing return to scale

' $t$ ' test was used to know whether $\Sigma b$ i was significantly deviating from unity or not

$t=\frac{\sum b i-1}{S . E . \text { of bi } i}=\frac{\sum b i-1}{\left.\sqrt{\left(C_{11}\right.}+C_{22} \ldots+C_{n n}+2 C_{12}+2 C_{13} \ldots+2 C_{m n}\right)}$

Where,

$\mathrm{C}_{11}, \mathrm{C}_{22}, \mathrm{C}_{12}, \mathrm{C}_{13}$ are the elements of variance, covariance obtained from inverse matrix.

\section{Results and Discussion}

Resource use efficiency, marginal value productivity and return to scale of cashewnut cultivation

The regression coefficient $\left(b_{i}\right)$, standard error (SE), return to scale $\left(\Sigma b_{i}\right)$ and coefficient of multiple determinations $\left(\mathrm{R}^{2}\right)$ worked out for the different categories of cashew growers in the study area are presented in Table 1. CobbDouglas production function was used for the estimation of the functional relationship between the different inputs used and the output. The main objective of this analysis was to find out, the efficiency of various factors employed in the production process. Simple correlation matrices for all the independent variables were worked out for testing the existence of multicolinearity. Since the problem of multicolinearity was not observed, then steps were taken for the regression analysis. It was seen from the table that in case of small farms, manures and fertilizers was highly significant at one per cent level of probability and the inputs like raw cashewnut, labour, insecticides \& pesticides and irrigation were significant at five per cent level of probability. But in case of miscellaneous expenditures it was not significant. It showed that raw cashewnut, labour, manures and fertilizers and insecticides and pesticides, irrigation have a positive impact towards the income from cashewnut. In this case, the elasticity coefficient for manures and fertilizers was 0.66 which means that one per cent increase in manures and fertilizers costs led on an average to about 0.66 per cent increase in the income from cashewnut crop, holding other variables like rawnut, labour, insecticides, pesticides, irrigation miscellaneous costs, constant at their geometrical mean level. The sum of regression coefficient $\left(\Sigma b_{i}\right)$ in case of small farms was 1.258 showing an increasing return to scale. The coefficient of multiple determinations $\left(\mathrm{R}^{2}\right)$ was 0.824 which would imply that $82 \%$ per cent variation in income of small cashewnut grower was explained by the included input costs variable. This indicates the goodness of fit of estimated regression function to the given data. The left out variation in the income of the cashewnut grower was due to omitted variables like management factors, social factor, climatic factors etc. If there is one per cent increase in the costs of omitted variables, there could be 0.18 per cent increase in the mean income of the crop.

In case of medium farms the regression coefficients associated with labour, was highly significant at one per cent level of probability whereas the coefficient for raw nut, manures and fertilizers, irrigation were significant at five per cent level of probability. The regression coefficient for raw nut, labour, manures \& fertilizers, insecticides \& pesticides, irrigation and miscellaneous costs were $0.07,0.41,0.70,0.06,0.08$ and 0.01 respectively. The magnitude of $\Sigma b_{i}$ being 1.357 was indicating increasing return to scale. The magnitude of $\mathrm{R}^{2}$ indicated that about 90 per cent of the variations in dependent variables i.e. gross return from cashewnut cultivation were explained by the independent variables like raw nut, labour, 
manures and fertilizers, insecticides and pesticides and irrigation.

In case of large farm, the regression coefficients for raw cashew nut was 0.05 and it was significant at five per cent level of probability, which means that increase in expenditure on seed materials will increase the income by about 0.05 per cent. The elasticity coefficient for manures and fertilizers was highly significant at one per cent level of probability. The magnitude of regression coefficient of 0.58 in case of manures and fertilizers indicated that one per cent increase in manures and fertilizers costs led on an average to about 0.58 per cent increase in the income of cashewnut crop, holding other remaining variables constant at their geometric mean level. The magnitude of $\Sigma b_{i}$ was 1.124 indicating an increasing return to scale. The coefficient of multiple determination $\left(\mathrm{R}^{2}\right)$ being 0.862 indicated the goodness of fit of the estimated regression function. It was evident from the regression analysis, the influence of raw nut, labour, manures and fertilizers, insecticides and pesticides, irrigation were significant at one per cent or five per cent level of probability. In all the categories of farms, the other working expenditure or miscellaneous item was not significant which was due to the less variation in the amount of cost per hectare of the crop and hence they could not explain the variation in the income of the crop enterprise.

Table.1 Regression coefficient (bi), Standard error (S.E.), Test of significance (t), Return to scale $\left(\sum\right.$ bi) and Coefficient of multiple determinations $\left(\mathrm{R}^{2}\right)$ obtained for Cashewnut cultivation by different categories of farms

\begin{tabular}{|c|c|c|c|c|c|}
\hline Sl.no & Items & Parameters & Small & Medium & Large \\
\hline \multirow[t]{3}{*}{1.} & Cost of Raw Cashewnut $\left(\mathrm{X}_{1}\right)$ & $\mathbf{b}_{1}$ & $0.046^{*}$ & $0.072 *$ & $0.054 *$ \\
\hline & & SE & 0.021 & 0.033 & 0.024 \\
\hline & & $\mathbf{t}$ & 2.190 & 2.182 & 2.250 \\
\hline \multirow[t]{3}{*}{2.} & Labour $\left(\mathbf{X}_{2}\right)$ & $\mathbf{b}_{2}$ & $0.352 *$ & $0.415 * *$ & $0.212 *$ \\
\hline & & SE & 0.144 & 0.142 & 0.089 \\
\hline & & $\mathbf{t}$ & 2.444 & 2.922 & 2.382 \\
\hline \multirow[t]{3}{*}{3.} & Manures \&Fertilizers $\left(\mathbf{X}_{3}\right)$ & $\mathbf{b}_{3}$ & $0.665 * *$ & $0.708^{*}$ & $0.583 * *$ \\
\hline & & SE & 0.228 & 0.318 & 0.196 \\
\hline & & $\mathbf{t}$ & 2.916 & 2.226 & 2.974 \\
\hline \multirow[t]{3}{*}{4.} & Insecticides \& Pesticides $\left(\mathbf{X}_{4}\right)$ & $\mathbf{b}_{4}$ & $0.114^{*}$ & 0.062 & $0.156^{*}$ \\
\hline & & SE & 0.052 & 0.053 & 0.057 \\
\hline & & t & 2.192 & 1.170 & 2.737 \\
\hline \multirow[t]{3}{*}{5.} & Irrigation $\left(\mathbf{X}_{5}\right)$ & $\mathbf{b}_{5}$ & $0.057 *$ & $0.081 *$ & $0.103 *$ \\
\hline & & SE & 0.027 & 0.031 & 0.044 \\
\hline & & $\mathbf{t}$ & 2.111 & 2.613 & 2.341 \\
\hline \multirow[t]{3}{*}{6.} & Miscellaneous Costs $\left(\mathbf{X}_{6}\right)$ & $\mathbf{b}_{6}$ & 0.024 & 0.019 & 0.016 \\
\hline & & SE & 0.023 & 0.020 & 0.024 \\
\hline & & $\mathbf{t}$ & 1.043 & 0.950 & 0.667 \\
\hline 7. & Return to scale & $\left(\sum \mathbf{b i}\right)$ & 1.258 & 1.357 & 1.124 \\
\hline 8. & Coefficient of multiple determination & $\left(\mathbf{R}^{2}\right)$ & 0.824 & 0.907 & 0.862 \\
\hline 9. & No. of sample farm & n & 36 & 30 & 24 \\
\hline
\end{tabular}


Table.2 Marginal Value Product (MVP), Marginal Factor Cost (MFC) and Ratio of MVP and MFC of Cashewnut Cultivation by Different Categories of Farms

\begin{tabular}{|c|c|c|c|c|c|c|c|}
\hline \multirow[t]{2}{*}{$\begin{array}{l}\text { Sl. } \\
\text { No. }\end{array}$} & Items & $\begin{array}{l}\text { Raw } \\
\text { cashew } \\
\text { nut }\end{array}$ & Labour & $\begin{array}{l}\text { Manures } \\
\& \\
\text { Fertilizers }\end{array}$ & $\begin{array}{l}\text { Insecticides } \\
\& \\
\text { Pesticides }\end{array}$ & Irrigation & Miscellaneous \\
\hline & & $\mathbf{X}_{1}$ & $\mathbf{X}_{2}$ & $\mathbf{X}_{3}$ & $\mathbf{X}_{4}$ & $\mathbf{X}_{5}$ & $\mathbf{X}_{6}$ \\
\hline \multirow[t]{4}{*}{1.} & \multicolumn{7}{|l|}{ Small Farm } \\
\hline & MVP & 1.358 & 1.674 & 2.312 & 2.107 & 1.028 & 1.126 \\
\hline & $\mathrm{MFC}$ & 1.0 & 1.0 & 1.0 & 1.0 & 1.0 & 1.0 \\
\hline & MVP/MFC & $1.358 *$ & $1.674 *$ & $2.312 * *$ & $2.107 *$ & $1.028 *$ & 1.126 \\
\hline \multirow[t]{4}{*}{2.} & \multicolumn{7}{|c|}{ Medium Farm } \\
\hline & MVP & 1.592 & 2.145 & 2.525 & 1.631 & 1.092 & 1.217 \\
\hline & $\mathrm{MFC}$ & 1.0 & 1.0 & 1.0 & 1.0 & 1.0 & 1.0 \\
\hline & MVP/MFC & $1.592 *$ & $2.145 * *$ & $2.525^{*}$ & 1.631 & $1.092 *$ & 1.217 \\
\hline \multirow[t]{4}{*}{3.} & \multicolumn{7}{|l|}{ Large Farm } \\
\hline & MVP & 1.372 & 1.828 & 2.514 & 2.106 & 1.112 & 1.465 \\
\hline & $\mathrm{MFC}$ & 1.0 & 1.0 & 1.0 & 1.0 & 1.0 & 1.0 \\
\hline & MVP/MFC & $1.372 *$ & $1.828^{*}$ & $2.514 * *$ & $2.106^{*}$ & $1.112 *$ & 1.465 \\
\hline
\end{tabular}

The basic criteria of efficient resource use requires that the marginal value product (MVP) of the input just covers, the factor costs (MFC) as such for evaluation of resource use efficiency (Table 2). The ratio MVP and MFC ratio was positive and greater than one. The greater than unit and it is significant in case of inputs like raw nut, labour, manures and fertilizers, insecticides and pesticides etc.

Its significance indicated the possibility of additional use of these inputs to achieve the optimum level. The above findings suggest that there is not accepting the hypothesis that the productivity of resources remain same in all categories of farms.

On the basis of the above findings and discussions of the study the following policy measures can be suggested for improvement in production of cashewnut.
Input delivery system should be based on the single window approach which encourages in the study area for timely, easy and convenient availability of inputs to cashewnut cultivators.

Efforts should be made towards appraising the cultivators of appropriate techniques and application of modern inputs for better production of cashewnut. Moreover, cashewnut cultivation needs high investment and capital, the cashew growers should be provided with adequate financial support mainly through co-operatives to provide modern inputs supply and proper disposal of their produce effectively.

Apart from the production of cashewnut suitable at different soil and climatic conditions the Government should take necessary steps for better marketing of cashewnut so that farmers can get remunerative price for their product. 
There is a felt need for a linkage and full cooperation between the state government, financial institutions, researchers, scientists, extension workers and cashewnut growers on different advanced technological aspects of cashewnut cultivation towards better production and help the farmers to get remunerative prices which ultimately reduce hunger and poverty from the society.

Cashewnut in Garo Hills region of Meghalaya is found to be economic feasible which can be more beneficial to reducing the costs of production through intervention of modern techniques in cultivation of the crop.

The farmers of Garo hills region are resource poor and unable to afford the input costs as well as expenditures for marketing of cashew produces. Therefore, the financial support is necessary for the cashew farmers through inclusive credit facilities.

\section{References}

DCR. 2011. Vision 2030. Directorate of Cashew Research, Puttur, Karnataka, India.

Ganapathi, H.A. and Akash, S.B. 2013. Constraints of farmers in cashew production - A case study of Udupi district of Karnataka State. Cashew Bulletin 51(7): 7-11.

Haque, T. 2006. Resource Use Efficiency in Indian Agriculture, Ind. Jn. of Agri. Econ. Vol. 61(1): 65-76

Sajeev, M.V. and Saroj, P.L. 2014. Technology utilization and its socio- economic determinants among cashew farmers of Karnataka. Indian Research Journal of Extension Education 14(3): 59-65.

Sajeev, M.V. and Saroj, P.L. 2015. Social and economic benefits of cashew (Anacardium occidentale) cultivation in Dakshina Kannada, Karnataka: An analysis of the impact, its determinants and constraints. Indian Journal of Agricultural Sciences 85(6): 821-826.

Sajeev, M.V., Saroj P.L. and Meera Manjusha, A.V. 2015. Technology adoption and socio-economic determinants of cashew farming in North Kerala. Journal of Plantation Crops 43(1): 9-16.

Sajeev, M.V., Saroj, P.L. and Lakshmisha, R. 2014a. Technology impacts on area, production and productivity of cashew in Dakshina Kannada district, Karnataka. Journal of Plantation Crops 42(1): 62-69.

Venkattakumar, R. 2006. Socio-economic impact of cashew cultivation in Kannur District of Kerala, India. Journal of Plantation Crops 34(3): 709-714.

Venkattakumar, R. 2008. Socio-economic impact of cashew cultivation in Sindhudurg district of Maharshtra. Journal of Plantation Crops 36(2): 117122.

Venkattakumar, R. 2009. Socio-economic factors for cashew production and implicative strategies: An overview. Indian Research Journal of Extension Education 9(3): 55-62.

\section{How to cite this article:}

Lakshmi Dhar Hatai. 2019. Resource Use Efficiency of Cashewnut in West Garo Hills of Meghalaya. Int.J.Curr.Microbiol.App.Sci. 8(07): 1844-1850.

doi: https://doi.org/10.20546/ijcmas.2019.807.219 